https://helda.helsinki.fi

The significance of the activity of glycogen debranching enzyme in glycolysis in porcine and bovine muscles

Ylä-Ajos, Maria

Elsevier

2006

Meat Science. 2006. 72(3): 532-538.

http://hdl.handle.net/1975/691

http://dx.doi.org/10.1016/j.meatsci.2005.09.004

Downloaded from Helda, University of Helsinki institutional repository.

This is an electronic reprint of the original article.

This reprint may differ from the original in pagination and typographic detail.

Please cite the original version. 


\section{The Significance of the Activity of Glycogen Debranching Enzyme in Glycolysis in Porcine and Bovine Muscles}

Maria Ylä-Ajos*, Marita Ruusunen, Eero Puolanne

Department of Food Technology, PO Box 66, 00014 University of Helsinki, Finland

Correspondence to: Maria Ylä-Ajos

Department of Food Technology

PO Box 66, (Agnes Sjöbergin katu 2)

00014 University of Helsinki

FINLAND

Tel:

+358919157948

Fax:

+358919158460

E-mail:

maria.yla-ajos@helsinki.fi

* Corresponding author 


\section{Abstract}

The purpose of the study was to examine the activity of glycogen debranching enzyme, GDE, in porcine and bovine muscles differing in rate of contraction and in oxidative capacity. The activity of GDE, the activity of phosphorylase, total glucose content, lactate content and $\mathrm{pH}$ were measured from meat samples taken 35 min post-mortem and ultimate $\mathrm{pH} 24$ or $48 \mathrm{~h}$ post-mortem.

Both GDE and phosphorylase are needed for the complete degradation of glycogen. In porcine muscles the activities of these glycogen degrading enzymes were higher than in bovine muscles. The activities were increasing with the increasing fast twitch and glycolytic character of a muscle of a given species. However, the increase in the activity of phosphorylase was greater than the increase in the activity of GDE. It was concluded that the GDE may restrict the rate of glycolysis in fast twitch muscles.

Keywords: Glycogen debranching enzyme; Phosphorylase; Oxidative and glycolytic muscles; Pig; Cattle

\section{Introduction}

The rate and extent of $\mathrm{pH}$ decrease in muscles post-mortem are important factors determining meat quality (Bendall \& Swatland, 1988; Briskey, 1964; Monin \& Ouali, 1991). The pH decrease is a result of efforts to maintain the ATP level constant by the anaerobic breakdown of glycogen to lactate. Normally higher rate of ATP turnover (Pearson \& Young, 1989; Pösö \& Puolanne, 2004) and shorter time to onset of anaerobic glycolysis due to lower oxygen stores (Hamm \& El-Badawi, 1991; Livingston \& Brown, 1981; Pearson \& Young, 1989) is observed in porcine than in bovine muscles, thus the rate of post-mortem $\mathrm{pH}$ decrease being faster in the former. 
Muscles can be classified into three groups according to the contractile and metabolic characteristics of their main fibre type (fast twitch and glycolytic (FG), slow twitch and oxidative (SO), fast twitch and oxidative (FOG)) (Pearson \& Young, 1989). In living muscles, SO fibres tend to maintain their energy-rich phosphate levels aerobically, while FG and FOG muscles have a greater ability to maintain their ATP supply anaerobically (Pearson \& Young, 1989), thus the post-mortem rate and extend of $\mathrm{pH}$ decrease are higher in FG than in SO muscles.

After slaughter, the $\mathrm{pH}$ decreases to the ultimate values of around 5.4-6.3, depending on the type of a muscle (Bendall \& Swatland, 1988; Fernandez \& Tornberg, 1991; Rao \& Gault, 1989 ) if the glycogen content in muscles before slaughter is not a limiting factor (Henckel, Karlsson, Jensen, Oksbjerg, \& Petersen, 2002; Przybylski, Vernin \& Monin, 1994). However, Immonen and Puolanne (2000) showed that some glycogen always remains in bovine muscles after the post-mortem reaction sequence, and in muscles with $\mathrm{pH}_{\mathrm{u}}$ lower than 5.75 the residual glycogen content varied considerably, from 10 to $85 \mathrm{mmol} / \mathrm{kg}$ meat. Several factors have been suggested to stop post-mortem glycolysis, including adenosine monophosphate deficiency (Scopes, 1971), a shortage of ADP or glucose (van Laack, Kauffman \& Greaser, 2001) and inhibition of glycolytic enzymes by pH decrease (Pearson \& Young, 1989). Kylä-Puhju, Ruusunen and Puolanne (2005) suggested that in some cases post-mortem glycolysis may be delayed by the inhibition of glycogen debranching enzyme due to muscle temperature decrease.

The degradation of glycogen is achieved by cooperation of two enzymes: glycogen phosphorylase (PHOS) and glycogen debranching enzyme (GDE) (Brown \& Brown, 1966). Glycogen molecules consist of branched glucose chains attached to protein core (Goldsmith, Sprang \& Fletterick, 1982; Gunja-Smith, Marshall, Mercier, Smith \& Whelan, 1970; 
Meléndez-Hevia, Waddell \& Shelton, 1993). In vivo most of the enzymes needed in glycogen metabolism are bound to these glycogen-protein particles (Lees, Chen \& Williams, 2004; Nelson, White \& Watts, 1972; Taylor, Cox, Kernohan \& Cohen, 1975). The GDE breaks down the branching points of glycogen (so-called limit dextrin state), enabling the further action of PHOS (Brown \& Brown 1966; Nelson, Kolb \& Larner 1969).

The activity of PHOS has been studied quite extensively in meat production animals, particularly in pigs (e.g. Dalrymple, Kastenschmidt \& Cassens, 1973; Estrade, Ayoub, Talmant \& Monin, 1994; Fernandez, Neyraud, Astruc \& Sante, 2002; Monin, MejenesQuijano, Talmant \& Sellier, 1987; Schwägele, Lopez Buesa \& Honikel, 1996; Suuronen, 1995) and also in cattle (Talmant, Monin, Briand, Dadet \& Briand, 1986). However, less attention has been paid to GDE despite suggestions of its role in slowing down the rate of post-mortem glycogenolysis and thus glycolysis, particularly when the glycogen limit dextrin state is concerned (Kylä-Puhju et al., 2005; Taylor et al., 1975). Hence, the GDE may have an influence on formation of PSE meat in pig, on tenderness and on formation of heat ring in cattle and on the shelf-life of meat from both species.

The aim of the present work was to study the activity of GDE and the relationship between the activities of PHOS and GDE in porcine and in bovine muscles. The purpose was to examine muscles with differences in rate of contraction (slow and fast) as well as in aerobic capacity (oxidative and glycolytic). 


\section{Materials and methods}

\subsection{Animals and sampling}

Muscle samples from 27 pigs (fast twitch and glycolytic (FG): M. longissimus dorsi, $M$. semimembranosus; slow twitch and oxidative (SO): $M$. infraspinatus, $M$. masseter) and from 19 bovines (FG: M. longissimus dorsi and SO: M. masseter) were obtained from a commercial abattoir about 35 min after the stunning. The samples were cut into small pieces, frozen and stored in liquid nitrogen. Freezing took place within 1 min of sampling. The GDE analyses were made within one week of sampling.

\subsection{Biochemical analyses}

The activity of GDE was determined using the method of Nelson, Palmer \& Larner (1970) with minor modifications (Kylä-Puhju et al., 2005). The method was based on monitoring the change in absorbance after certain reaction times, due to conversion of limit dextrin to glycogen by GDE. The activity of GDE was calculated from the slope of the linear portion of the absorbance curve. The reaction times used were 1, 2.5, 4 min for porcine masseter and infraspinatus muscles, 1, 1.5, 2.5 min for porcine longissimus dorsi muscle, 1, 2, 3 min for porcine semimembranosus muscle and 1, 3,6 min for bovine muscles. The reaction times were determined in preliminary experiments for each muscle. In addition, the absorption spectra between $375 \mathrm{~nm}$ and $800 \mathrm{~nm}$ of the method blank and the reaction mixtures were obtained to ensure the conversion of limit dextrin to glycogen (results not shown). GDE is a monomeric protein containing two independent catalytic activities: a glycan transferase (EC 2.4.1.25) and amylo-1,6-glucosidase (EC 3.2.1.33) (Nelson et al., 1970; Gordon, Brown \& Brown, 1972; White \& Nelson, 1974; Taylor et al., 1975). The method used in the present study measures the combined action of GDE. 
Lactate and glycogen determinations were made concomitantly. Muscle samples were homogenised in ice-cold 0.1 M phosphate buffer ( $\mathrm{pH}$ 7.0) with a Polytron homogeniser. Lactate content was determined spectrophotometrically $(365 \mathrm{~nm})$ using a commercial kit (Boeringer-Mannheim no. 139 084). Glycogen content was determined as total glucose content, i.e. the resulting value includes also free glucose and glucose phosphates present in the muscle. Muscle homogenate was hydrolysed in $1 \mathrm{M} \mathrm{HCl}$ at $100{ }^{\circ} \mathrm{C}$ for $2 \mathrm{~h}$, after which $\mathrm{pH}$ was adjusted to 6.5-7.5 (Lowry \& Passoneau, 1973) and glucose was determined with Roche diagnostic kit no. 1447521.

Glycolytic potential was calculated according to Monin et al. (1987): glycolytic potential $($ mmol LA equiv. $/ \mathrm{kg})=2([$ glycogen $]+[$ glucose $]+[$ glucose-6-phosphate $])+[$ lactate $]$. In the present study, the formula was used in form: glycolytic potential $=2[$ total glucose content $]+$ [lactate].

The activity of phosphorylase was measured spectrophotometrically (absorbance $340 \mathrm{~nm}$, Perkin Elmer Lambda 2 spectrometer, Überlingen, Germany) according to Bass et al. (1969) following the release of glucose-1-phosphate from glycogen with L-cystein, NaDP (N8129, Sigma-Aldrich, St. Luis, USA), glucose-1,6-diphosphate, AMP, phosphoglucomutase (rabbit muscle, 79440, Fluga Chemie GmbH, Buchs, Switzerland) and glucose-6-phosphatedehydrogenase (127671, Roche, Indiapolis, USA).

The $\mathrm{pH}$ values were measured from meat extracts $(1 \mathrm{~g}$ muscle $+10 \mathrm{ml} 5 \mathrm{mM} \mathrm{Na-Iodoacetic}$ acid solution) using a Knick Portamess 752 pH-meter equipped with a Mettler-Toledo Inlab 427 electrode. Extracts were made from muscles which were frozen immediately after sampling $\left(\mathrm{pH}_{35}\right)$, and from samples which were frozen $24 \mathrm{~h}$ (porcine muscles) or $48 \mathrm{~h}$ (bovine 
muscles) post mortem, ultimate $\mathrm{pH}\left(\mathrm{pH}_{\mathrm{u}}\right)$. The frozen samples were homogenised in ice cold Na-Iodoacetic acid and the $\mathrm{pH}$ values were measured at room temperature.

The reproducibility of the assays was determined as follows: a large muscle sample was ground in liquid nitrogen, divided into small pieces and stored at $-80{ }^{\circ} \mathrm{C}$. This sample was analysed every time the samples were analysed. The coefficients of variation (CV) were $\pm 8.2 \%$ for lactate content, $\pm 13.9 \%$ for glycogen content, $\pm 11.8 \%$ for activity of PHOS and $\pm 21.3 \%$ for activity of GDE. The GDE activity measurements were made in triplicate, glycogen content, activity of PHOS and $\mathrm{pH}$ measurements in duplicate.

\subsection{Statistical analysis}

The General Linear Model was applied when calculating the estimated marginal means and standard errors of activity of GDE, activity of PHOS, PHOS/GDE ratio, glycogen content, lactate content, glycolytic potential, $\mathrm{pH}_{35}$ and $\mathrm{pH}_{\mathrm{u}}$ for porcine muscles. The model included a fixed effect of muscle and random effect of slaughter date to compensate for environmental effects. When the error variances were unequal, Dunnet's T3 test was used (for porcine PHOS, GDE, $\mathrm{pH}_{35}$, glycogen, lactate, GP), otherwise Tukey's HSD test (for porcine PHOS/GDE ratio, $\mathrm{pH}_{\mathrm{u}}$ ). When testing the differences in bovine muscles, independent samples t-test was applied. Estimated marginal means were considered to be significantly different when $\mathrm{P}<0.05$. Pearson correlations were calculated between parameters of a given muscle. Data analysis was conducted using SPSS 10.0 for Windows (SPSS Inc., 1994).

\section{Results}

\subsection{Porcine muscles}

The activities of glycogen degrading enzymes were the highest in FG longissimus dorsi muscle and the lowest in SO masseter muscle (Table 1). The activity of GDE was more than 
two times higher and the activity of PHOS more than three times higher in the FG muscles than in the SO ones. Thus, the ratio between the two glycogen degrading enzymes PHOS/GDE was higher in the FG muscles than in the SO muscles, but was similar in both SO muscles and in both FG muscles, respectively. Since GDE and PHOS activities were not measured in the same units the ratio does not quantify the real difference between the activities of these enzymes within a muscle. The ratios between muscles, however, are comparable.

In FG muscles the glycolytic potential was higher than in the SO muscles (Table 1). Furthermore, in the FG muscles the post mortem $\mathrm{pH}$ decrease was faster and the ultimate $\mathrm{pH}$ was lower than in SO muscles. The glycolytic potential and $\mathrm{pH}$ at $35 \mathrm{~min}$ post-mortem were the lowest and the $\mathrm{pH}_{\mathrm{u}}$ was the highest in the infraspinatus muscle.

The activity of PHOS correlated positively with the ultimate $\mathrm{pH}$ in FG longissimus dorsi muscle, $r=0.588 \mathrm{p}=0.001$, and semimembranosus muscle, $r=0.421 \mathrm{p}=0.029$. Furthermore, in the same muscles the correlation between the activity of PHOS and glycolytic potential was negative, $r=-0.439 \mathrm{p}=0.022$ and $\mathrm{r}=-0.416 \mathrm{p}=0.031$, respectively. However, no correlation between the activity of GDE and the measured parameters was found.

\subsection{Bovine muscles}

In bovine muscles the activities of glycogen degrading enzymes were also higher in FG longissimus dorsi muscle than in SO masseter muscle (Table 2). The activity of GDE was almost two-fold higher in longissimus dorsi muscle compared to masseter muscle. However, the activities were lower than in porcine muscles. Again, the difference was even greater in the activity of PHOS, and the PHOS/GDE ratio was almost three times higher in longissimus dorsi muscle than in masseter muscle. 
As expected, glycolytic potential and $\mathrm{pH}_{35}$ were higher and $\mathrm{pH}_{\mathrm{u}}$ was lower in longissimus dorsi muscle than in masseter muscle (Table 2). No significant Pearson correlations either between GDE and measured parameters or between PHOS and measured parameters were found (results not shown).

The activity of GDE did not correlate with $\mathrm{pH}_{\mathrm{u}}$ for either porcine or bovine muscles. However, when the results for the porcine muscles (Fig. 1a) or bovine muscles (Fig. 1b) were combined, a trend could be seen. The ultimate $\mathrm{pH}$ remained high in $\mathrm{SO}$ muscles where also the activity of GDE was low. However, it must be kept in mind that there were differences also in the activity of PHOS and the glycogen content between individual muscles of a given animal and it is well known that the glycogen content has an influence on muscle $\mathrm{pH}_{\mathrm{u}}$.

\section{Discussion}

\subsection{Porcine versus bovine muscles}

The rate of the hydrolysis of ATP determines the rate of post mortem glycolysis (Bendall, 1973), which is higher in porcine than in bovine muscles (Pearson \& Young, 1989). The physiological purpose of glycolysis is to maintain the ATP level constant in the muscle (Hamm, 1977), leading to anaerobic degradation of glycogen after slaughter. The results of the present study indicated that porcine muscles have a higher capacity to degrade glycogen than bovine muscles. The GDE activity was about two times higher in porcine muscles than in corresponding bovine muscles. Also the activity of PHOS was somewhat higher in the porcine muscles.

The rate of glycolysis is affected by the rate of ATP turnover, aerobic capacity and the activity of glycolytic enzymes. Firstly, the myofibrillar ATPase activity (Laborde, Talmant \& Monin, 1985; Talmant et al., 1986) and the ATP turnover rate are higher in porcine muscles 
compared to bovine muscles. The rate of ATP turnover in porcine longissimus dorsi muscle can be as high as $4 \mu \mathrm{mol} \mathrm{ATP} /\left(\mathrm{min}^{*} \mathrm{~g}\right)$ as has been reported for of stress susceptible Pietrain pigs (Bendall, 1973). Even though this does not represent a normal case, it is much higher than the ATP turnover rate of $0.15 \mu \mathrm{mol} \mathrm{ATP} /\left(\mathrm{min}^{*} \mathrm{~g}\right)$ for bovine longissimus dorsi muscle during the first three hours post-mortem (Hamm, 1977). Secondly, porcine muscles are less aerobic and produce ATP by oxidative phosphorylation for a shorter period after slaughter than bovine muscles. Thus, the delay in the time of onset of anaerobic glycolysis in bovine muscles is a result of high amounts of oxygen binding myoglobin, abundant mitochondria and high activity of oxidative enzymes (Lawrie, 1985, Pösö \& Puolanne, 2004). Thirdly, the activities of glycolytic enzymes, such as phoshorylase (Talmant et al. 1986), glyceraldehydes3-phosphate dehydrogenase (pig, Laborde, Talmant \& Monin, 1985; bovine, Talmant et al., 1986) and lactate dehydrogenase (Hamm \& El-Badawi, 1991) depending, however, on the muscle concerned, are higher in porcine muscles than in bovine muscles. The present study showed that besides the PHOS activity, the activity of GDE is also higher in porcine muscles than in bovine muscles. Together these factors explain the faster $\mathrm{pH}$ decrease after slaughter in porcine muscles compared with bovine muscles.

In the present study, the slower rate of anaerobic glycolysis in the bovine longissimus dorsi muscle shortly after slaughter was seen as a higher $\mathrm{pH}$ at the sampling compared to the corresponding porcine muscle. Although this difference was not observed between the masseter muscles, porcine muscles can be considered on average a more fast twitch and glycolytic type than bovine muscles, as stated by Talmant et al. (1986). The GP's for porcine infraspinatus, longissimus dorsi and semimembranosus muscles were similar to those reported by Fischer and Dobrowolski (2002) for the same muscles. However, the GP of bovine FG longissimus dorsi muscle was higher than in the corresponding porcine muscle, which partly originates from the sensitivity of pigs to pre slaughter stress. Porcine muscles are 
very glycolytic and glycogen reservoirs begin to degrade even under light stress whereas in more oxidative bovine muscles the break down of glycogen begins as a consequence of longterm stress (Lawrie, 1985). The GP and $\mathrm{pH}_{35}$ were very low particularly in porcine infraspinatus muscle.

\subsection{Porcine and bovine fast twitch and glycolytic versus slow twitch and oxidative muscles}

The activities of GDE and PHOS increased with the fast twitch and glycolytic character of a muscle of a given animal. Tsutou et al. (1985) obtained similar results with rabbit slow and fast muscles. Both in pigs and in cattle, the activity of GDE was twice as high in FG muscles as in SO ones. However, there was even greater increase in the activity of PHOS. Several other papers have reported that enzymes in the pathway from glycogen to lactate are more active in FG muscles than in SO ones (Beecher, Cassens, Hoekstra \& Briskey, 1965b; Hamm \& El-Badawi, 1991; Laborde et al., 1985; Monin et al., 1987; Talmant et al. 1986). Until now, the role of the activity of GDE on glycogen degradation in the muscles of meat production animals has not been extensively studied.

Rapid glycolysis is not essential for SO muscles. In these muscles aerobic energy production is preferred, because of better blood supply, higher amounts of myoglobin, more mitochondria and more active pathway from glycogen through the Krebs cycle to $\mathrm{CO}_{2}$ and $\mathrm{H}_{2} \mathrm{O}$ than in $\mathrm{FG}$ ones (Beecher, Briskey \& Hoekstra, 1965a; Beecher et al. 1965b; Bendall, 1975; Laborde et al., 1985; Pearson \& Young, 1989; Talmant et al., 1986; Pösö \& Puolanne, 2004). Also the glycogen content is lower in SO than in FG muscles (Karlsson, Klont \& Fernandez, 1999; Lefaucheur et al., 1989; Monin et al., 1987) and similar results was obtained in the present study. The present study showed that besides lower PHOS activity, the activity of GDE was also lower in the SO muscles than in the FG muscles. Altogether, the fast glycolysis in FG muscles is caused by the high glycolytic potential in association with the high activity of 
glycogen degrading enzymes, allowing rapid conversion of glycogen into lactate.

Furthermore, the ultimate $\mathrm{pH}$ was lower in $\mathrm{FG}$ muscles than in $\mathrm{SO}$ ones as has been reported earlier (Beecher et al., 1965b; Bendall \& Swatland, 1988; Fernandez \& Tornberg, 1991; Hunt \& Hedrick, 1977; Laborde et al., 1985; Monin et al., 1987; Rao \& Gault, 1989; Talmant et al., 1986).

In porcine FG semimembranosus and longissimus dorsi muscles, the activity of PHOS correlated negatively with GP, different to the report of Estrade, Ayoub, Talmant \& Monin (1994) for porcine longissimus dorsi muscle. Furthermore, the activity of PHOS correlated positively with the ultimate $\mathrm{pH}$ in FG porcine muscles. The observed correlations could be due to faster pre mortem glycolysis in muscles that showed high activity of phosphorylase. Such a correlation was not found in SO muscles or in bovine muscles.

\subsection{The activity of GDE in relation to the activity of PHOS}

The PHOS/GDE ratio was higher in FG muscles than in SO ones, in both species. The activity of PHOS increased more than the activity of GDE with the increasing fast twitch and glycolytic character of a given animal, thus increasing the PHOS/GDE ratio. The ratio was lowest in bovine SO masseter muscle, but highest in bovine longissimus dorsi muscle. The authors have no explanation to the latter observation. The PHOS/GDE ratio is also higher in FG chicken breast muscle than in SO leg muscle, however, the values of the ratios are much higher than found in the present study (Ylä-Ajos, Ruusunen, Puolanne, unpublished data). In porcine muscles the ratio was relatively constant within a muscle type.

The lower PHOS/GDE ratios in all SO muscles compared to FG muscles indicated that glycogen degrading enzymes were more in balance in the SO muscles. Consequently, in SO muscles the degradation of glycogen may proceed without a delay caused by the low activity 
of GDE. Alternatively, the proportionally low activity of GDE in relation to the activity of PHOS in FG muscles may be a protective mechanism against a sudden $\mathrm{pH}$ decrease. FG muscles are capable for a short-term strenuous contractile activity, but they fatigue quite easily (Lawrie, 1985). Also the potential for amplification of the glycogenolytic cascade is much higher in FG muscles than in SO muscles (Cohen, 1978). Thus, in strenuous physical stress, a high PHOS/GDE ratio in FG muscles enables a short burst of glycolysis, which leads to a rapid increase in $\mathrm{H}^{+}$content. The high buffering capacity of FG muscles (Davey, 1960; Kylä-Puhju et al., 2004; Puolanne \& Kivikari, 2000; Rao \& Gault, 1989; Talmant et al. 1986) protects these muscles against a sudden $\mathrm{pH}$ decrease, but the proportionally low activity of GDE compared to the activity of PHOS may be needed to further restrain glycogenolysis.

\subsection{The potential role of GDE in muscle metabolism post-mortem}

The activity of GDE may play a role in controlling the rate of post-mortem $\mathrm{pH}$ decrease. Although the activity of GDE did not correlate with the $\mathrm{pH}_{35}$ or with the $\mathrm{pH}_{\mathrm{u}}$ for either porcine or bovine muscles, a negative relationship between the activity of GDE and $\mathrm{pH}_{\mathrm{u}}$ was seen when the results for individual muscles of a given species were combined (Figure $1 \mathrm{a}, \mathrm{b}$ ). However, one should bear in mind that there were differences also in glycogen content and activity of PHOS between individual muscles of a given animal. In the present study, the activity of GDE did not correlate with glycolytic potential within any muscle in either of the given species. However, Lees et al. (2004) demonstrated with rat skeletal muscle sarcoplasmic reticulum that an activity which leads to a reduction in muscle glycogen content, also reduces GDE content. Furthermore, Daly, Richards, Gibson, Gardner \& Thompson (2002) reported that the bovine longissimus dorsi muscles with higher glycogen content reached $\mathrm{pH} 6$ at higher temperatures during chilling than the muscles that contained less glycogen. Thus, post-mortem glycolysis was faster in animals having more glycogen indicating that substrate availability is one of the factors determining glycolytic rate. 
The present study was carried out with carcasses randomly selected from the slaughter line and thus representing a normal commercial situation. The activity of GDE may neither slow down nor stop the glycogenolysis in normal porcine or bovine muscles during normal postmortem reaction sequence. However, the possibility that the activity of GDE may have a critical role in glycogenolysis can not be excluded. This kind of a situation could arise when muscle glycogen is low at slaughter and the carcass is chilled rapidly. When the glycogen content is low, muscles end up in a situation where glycogen limit dextrin has to be broken down to keep on glycolysis. At this time GDE determines the rate and continuation of the $\mathrm{pH}$ decrease rather than phosphorylase. Furthermore, low activity of GDE may reduce the incidence of PSE meat by restraining fast glycolysis in porcine muscles, thus giving time for the temperature to decrease before reaching the critical $\mathrm{pH}$. GDE may also play a role in the formation of dark, coarse band (heat ring) as a result of rapid chilling in non-electrically stimulated bovine muscles. Orcutt, Dutson, Cornforth and Smith (1984) showed that the $\mathrm{pH}$ value of longissimus dorsi muscle was higher just beneath the subcutaneous fat cover than in the central regions at 12 and $24 \mathrm{~h}$ post mortem, but similar at $48 \mathrm{~h}$. They proposed that the slower glycolytic rate in the outer parts of the muscle was due to the higher chilling rate. Furthermore, Kylä-Puhju et al. (2005) showed that decrease in muscle temperature radically decreases the activity of GDE. Hence, the relationship of the activity of GDE both to the rate of $\mathrm{pH}$ fall and to the ultimate $\mathrm{pH}$ in muscles where glycogen content prior slaughter is low or high warrants further study.

\section{Conclusions}

In porcine muscles the activities of glycogen degrading enzymes, GDE and PHOS, are higher than in bovine muscles, thus providing a chance for rapid $\mathrm{pH}$ decrease. The activities of GDE and PHOS increase with the increasing fast twitch and glycolytic character of a muscle of a 
given animal. However, the increase in the activity of PHOS is greater than the increase in the activity of GDE and thus the latter enzyme may restrict the rate of glycolysis in fast twitch muscles.

\section{Acknowledgements}

The present study was supported by the Finnish Graduate School Program 'Applied

Bioscience - Bioengineering, Food \& Nutrition, Environment' (ABS) and the Finnish

Association of Academic Agronomists. The authors thank the slaughterhouses Koiviston

Teurastamo Oy and Paimion Teurastamo Oy for providing the muscle samples and for help in sampling. Laboratory Technician Irja Korhonen is acknowledged for her technical assistance in biochemical analyses.

\section{References}

Bass, A., Brdiczka, D., Eyer, P., Hofer, S., \& Pette, D. (1969). Metabolic differentiation of distinct muscle types at the level of enzymatic organization. European Journal of Biochemistry, 10, 198-206.

Beecher, G. R., Briskey, E. J., \& Hoekstra, W. G. (1965a). A comparison of glycolysis and associated changes in light and dark portions of the porcine semitendinosus. Journal of Food Science, 30, 477-486.

Beecher, G. R., Cassens, R. G., Hoekstra, W. G., \& Briskey, E. J. (1965b). Red and white fiber content and associated post-mortem properties of seven porcine muscles. Journal of Food Science, 30(6), 969-976.

Bendall, J. R. (1973). Postmortem changes in muscle. In G. H. Bourne, The Structure and Function of Muscle, Volume II, Structure, part 2 (pp. 243-309). New York: Academic Press.

Bendall, J. R. (1975). Cold-contracture and ATP-turnover in the red and white musclulature of the pig, post mortem. Journal of the Science of Food and Agriculture, 26(1), 55-71.

Bendall, J. R., \& Swatland, H. J. (1988). A review of the relationships of $\mathrm{pH}$ with physical aspects of pork quality. Meat Science, 24(2), 85-126.

Briskey, E. J. (1964). Etiological status and associated studies of pale, soft, exudative porcine musculature. Advances in Food Research, 13, 89-178.

Brown, D. H., \& Brown, B. I. (1966). Enzymes of glycogen debranching: amylo-1,6glucosidase (I) and oligo-1,4 $\rightarrow 1,4$-glucantransferase (II) . In S. P. Colowick \& N. O. Kaplan, Methods in Enzymology (pp. 515-524). New York: Academic Press.

Cohen, P. (1978). The role of cyclic-AMP-dependent protein kinase in the regulation of glycogen metabolism in mammalian skeletal muscle. Current Topics in Cellular Regulation, 14, 117-196. (a review).

Dalrymple, R. H., Kastenschmidt, L. L., \& Cassens, R. G. (1973). Glycogen and phosphorylase in developing red and white muscle. Growth, 37, 19-34. 
Daly, B. L., Richards, I., Gibson, P. G., Gardner, G. E., \& Thompson, J. M. (2002). Rate of $\mathrm{pH}$ decline in bovine muscle post-mortem - a benchmarking study. In Proceedings of the $48^{\text {th }}$ international congress of meat science (Vol. II, pp. 560-561), 25-30 August 2002, Rome, Italy.

Davey, C. L. (1960). The significance of carnosine and anserine in striated skeletal muscle. Archives of Biochemistry and Biophysics, 89, 303-308.

Estrade, M., Ayoub, S., Talmant, A., \& Monin, G. (1994). Enzyme activities of glycogen metabolism and mitochondrial characteristics in muscles of RN- carrier pigs (Sus scrofa domesticus). Comparative Biochemistry and Physiology. Biochemistry and Molecular Biology, 108(3), 295-301.

Fernandez, X., Neyraud, E., Astruc, T., \& Sante, V. (2002). Effects of halothane genotype and pre-slaughter treatment on pig meat quality. Part 1. Post mortem metabolism, meat quality indicators and sensory traits of m. Longissimus lumborum. Meat Science, 62(4), 429-437.

Fernandez, X., \& Tornberg, E. (1991). A review of the causes of variation in muscle glycogen content and ultimate $\mathrm{pH}$ in pigs. Journal of Muscle Foods, 2(3), 209-235.

Fischer, K., \& Dobrowolski, A. (2002). Topographic variation of the glycolytic potential in the muscles of slaughter pigs. Fleischwirtschaft, 82(2), 78-82. (in German).

Goldsmith, E., Sprang, S., \& Fletterick, R. (1982). Structure of maltoheptaose by difference Fourier methods and a model for glycogen. Journal of Molecular Biology, 156(2), 411427.

Gordon, R. B., Brown, D. H., \& Brown, B. I. (1972). Preparation and properties of the glycogen-debranching enzyme from rabbit liver. Biochimica Et Biophysica Acta, 289(1), 97-107.

Gunja-Smith, Z., Marshall, J. J., Mercier, C., Smith, E. E., \& Whelan, W. J. (1970). A revision of the Meyer-Bernfeld model of glycogen and amylopectin. FEBS Letters, 12(2), 101-104.

Hamm, R., \& El-Badawi, A. (1991). Aktivität und subzelluläre Verteilung der Lactatdehydrogenase in heller und dunkler Muskulatur von Rind und Schwein.[Activity and subcellular distribution of lactate dehydrogenase in light and dark muscle of cattle and swine.]. Fleischwirtschaft, 71(7), 813-816.

Hamm, R. (1977). Postmortem breakdown of ATP and glycogen in ground muscle: A review. Meat Science, 1(1), 15-39.

Henckel, P., Karlsson, A., Jensen, M. T., Oksbjerg, N., \& Petersen, J. S. (2002). Metabolic conditions in porcine longissimus muscle immediately pre-slaughter and its influence on peri-and post mortem energy metabolism. Meat Science, 62(2), 145-155.

Hunt, M. C., \& Hedrick, H. B. (1977). Profile of fiber types and related properties of five bovine muscles. Journal of Food Science, 42(2), 513-517.

Immonen, K., \& Puolanne, E. (2000). Variation of residual glycogen-glucose concentration at ultimate $\mathrm{pH}$ values below 5.75. Meat Science, 55(3), 279-283.

Karlsson, A. H., Klont, R. E., \& Fernandez, X. (1999). Skeletal muscle fibres as factors for pork quality. Livestock Production Science, 60, 255-269. (a review).

Kylä-Puhju, M., Ruusunen, M., Kivikari, R., \& Puolanne, E. (2004). The buffering capacity of porcine muscles. Meat Science, 67(4), 587-593.

Kylä-Puhju, M., Ruusunen, M., \& Puolanne, E. (2005). Activity of porcine muscle glycogen debranching enzyme in relation to $\mathrm{pH}$ and temperature. Meat Science, 69(1), 143-149.

Laborde, D., Talmant, A., \& Monin, G. (1985). Metabolic and contractile relationships of 30 porcine muscles. Relationship to ultimate post-mortem $\mathrm{pH}$. Reproduction, Nutrition, Development, 25(4), 619-628.

Lawrie, R. A. (1985). Meat Science. Oxford: Pergamon.

Lees, S. J., Chen, Y. T., \& Williams, J. H. (2004). Glycogen debranching enzyme is associated with rat skeletal muscle sarcoplasmic reticulum. Acta Physiologica Scandinavica, 181(2), 239-245. 
Lefaucheur, L., Le Dividich, J., Mourot, J., Monin, G., Ecolan, P., \& Krauss, D. (1991). Influence of environmental temperature on growth, muscle and adipose tissue metabolism, and meat quality in swine. Journal of Animal Science, 69, 2844-2854.

Livingston, D. J., \& Brown, W. D. (1981). The chemistry of myoglobin and its reactions. Food Technology, 35(5), 244-252.

Lowry, O. H. \& Passoneau, J. V. (1973). A flexible system of enzymatic analysis. New York: Academic Press.

Meléndez-Hevia, E., Waddell, T. G., \& Shelton, E. D. (1993). Optimization of molecular design in the evolution of metabolism: the glycogen molecule. The Biochemical Journal, 295(Pt 2), 477-483.

Monin, G., Mejenes-Quijano, A., \& Talmant, A. (1987). Influence of breed and muscle metabolic type on muscle glycolytic potential and meat $\mathrm{pH}$ in pigs. Meat Science, 20(2), 149-158.

Monin, G., \& Ouali, A. (1991). Muscle differentiation and meat quality. In R. A. Lawrie, Developments in Meat Science-5 (pp. 89-157). Essex, England: Elsevier Science Publishers LTD.

Nelson, T. E., Kolb, E., \& Larner, J. (1969). Purification and properties of rabbit muscle amylo-1,6-glucosidase-oligo-1,4-1,4-transferase. Biochemistry, 8(4), 1419-1428.

Nelson, T. E., Palmer, D. H., \& Larner, J. (1970). An investigation of the properties of rabbit muscle oligo-1,4--1,4-glucantransferase. Biochimica Et Biophysica Acta, 212(2), 269-280.

Nelson, T. E., White, R. C., \& Watts, T. E. (1972). The action of the glycogen debranching enzyme system in a muscle protein particle. Biochemical and Biophysical Research Communications, 47(1), 254-259.

Orcutt, M. W., Dutson, T. R., Cornforth, D. P., \& Smith, G. C. (1984). Journal of Animal Science, 58(6), 1366-1375.

Pearson, A. M. \& Young, R. B. (1989). Post mortem changes during conversion of muscle to meat. In: Muscle and Meat Biochemistry. San Diego, CA: Academic Press, cop.

Przybylski, W., Vernin, P., \& Monin, G. (1994). Relationship between glycolytic potential and ultimate $\mathrm{pH}$ in bovine, porcine and ovine muscles. Journal of Muscle Foods, 5(3), 245255.

Puolanne, E., \& Kivikari, R. (2000). Determination of the buffering capacity of postrigor meat. Meat Science, 56, 7-13.

Pösö, A. R., \& Puolanne, E. (2004). Carbohydrate metabolism in meat animals. In Proceedings of $50^{\text {th }}$ International Congress of Meat Science and Technology (pp. 52-64), 8-13 August 2004, Helsinki, Finland. (a review).

Rao, M. V., \& Gault, N. F. S. (1989). The influence of fibre-type composition and associated biochemical characteristics on the acid buffering capacities of several beef muscles. Meat Science, 26(1), 5-18.

Schwägele, F., Lopez Buesa, P. L., \& Honikel, K. O. (1996). Enzymological investigations on the causes for the PSE-syndrome. II. Comparative studies on glycogen phosphorylase from pig muscles. Meat Science, 44(1/2), 41-53.

Scopes, R. K. (1971). Mechanisms Controlling Glycolysis in Muscle. The Biochemistry of Post Mortem Glycolysis. In Proceedings of 17th European Meeting of Meat Research Workers (pp. 14-20), 6-10 September 1971, Bristol, England.

SPSS Inc. (1994). SPSS 6.1. for Windows Update. Chicago, IL. USA: SPSS Inc.

Suuronen, T. (1995). The relationship of oxidative and glycolytic capacity of longissimus dorsi muscle to meat quality when different pig breeds and crossbreeds are compared. Academic dissertation. University of Jyväskylä. Jyväskylä.

Talmant, A., Monin, G., Briand, M., Dadet, M., \& Briand, Y. (1986). Activites of metabolic and contractile enzymes in 18 bovine muscles. Meat Science, 18(1), 23-40. 
Taylor, C., Cox, A. J., Kernohan, J. C., \& Cohen, P. (1975). Debranching enzyme from rabbit skeletal muscle. Purification, properties and physiological role. European Journal of Biochemistry, 51(1), 105-115.

Tsutou, A., Nakamura, S., Negami, A., Nakaza, T., Kobayashi, T., Mizuta, K., Hashimoto, E., \& Yamamura, H. (1985). Comparison of enzyme activities on glycogen metabolism in rabbit slow and fast muscles. Comparative Biochemistry and Physiology. B: Comparative Biochemistry, 81(3), 641-645.

Van Laack, R. L. J. M., Kauffman, R. G., \& Greaser, M. L. (2001). Determinants of ultimate $\mathrm{pH}$ of meat. In Proceedings of the $47^{\text {th }}$ international congress on meat science and technology (Vol. I, pp. 22-26), 2001, Krakow, Poland.

White, R. C., \& Nelson, T. E. (1974). Re-evaluation of the subunit structure and molecular weight of rabbit muscle amylo-1,6-glucosidase-4-alpha-glucanotransferase. Biochimica Et Biophysica Acta, 365(1), 274-280. 
Figure 1a. The ultimate $\mathrm{pH}$ in relation to the activity of GDE in porcine muscles

Figure $1 \mathrm{~b}$. The ultimate $\mathrm{pH}$ in relation to the activity of GDE in bovine muscles

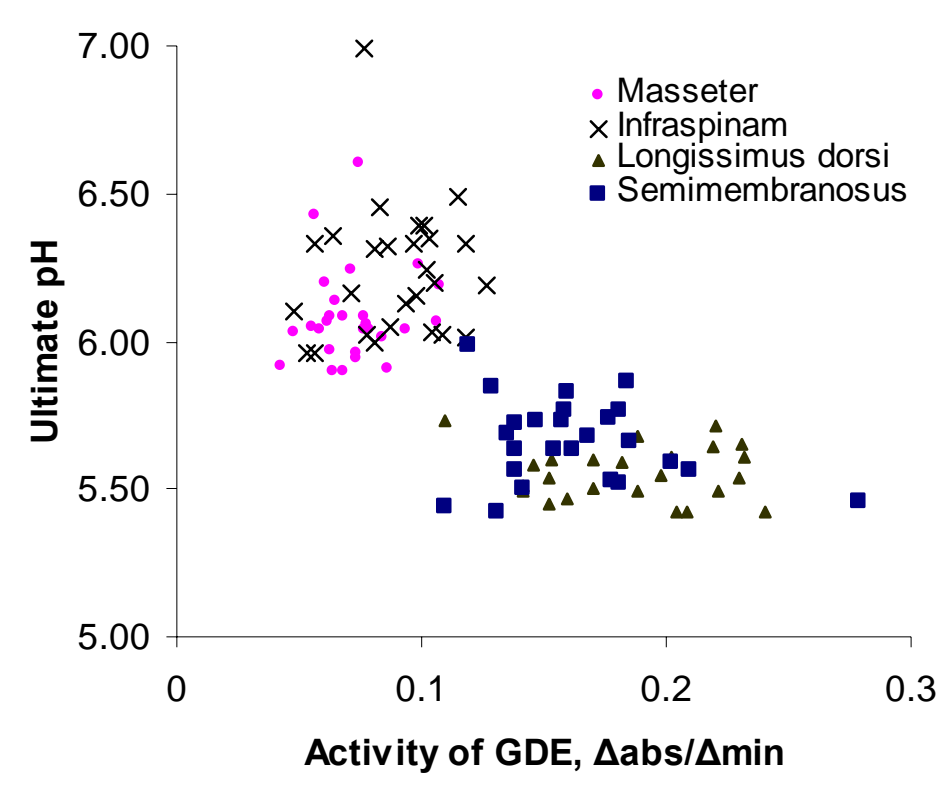

Figure 1a.

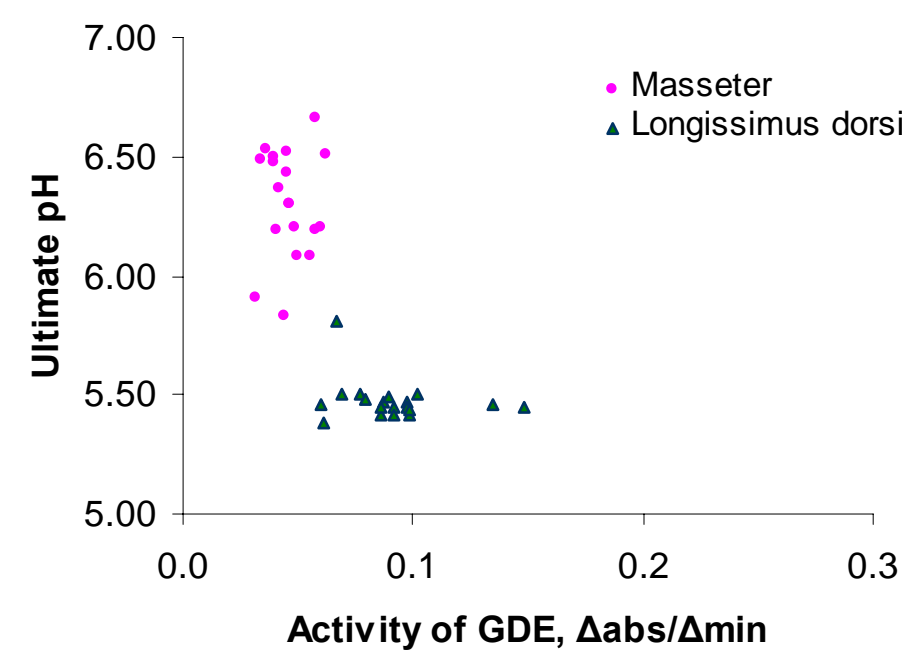

Figure 1b. 
Table 1 . The activity of GDE ( $\Delta \mathrm{abs} / \Delta \mathrm{min})$, the activity of PHOS (U/g muscle), the ratio between PHOS and GDE activities, glycolytic potential (mmol LA equiv./kg) and $\mathrm{pH}_{35}$ and $\mathrm{pH}_{\mathrm{u}}$ values in porcine muscles. $\mathrm{N}=27$.

\begin{tabular}{lccccc}
\hline & \multicolumn{2}{c}{$\begin{array}{c}\text { Slow Twitch and Oxidative } \\
\text { muscles }\end{array}$} & \multicolumn{2}{c}{ Fast Twitch and Glycolytic muscles } \\
& \multicolumn{2}{c}{$\begin{array}{c}\text { M. } \text { infraspinatus } \\
\text { M. masseter }\end{array}$} & $\begin{array}{c}\text { M. longissimus } \\
\text { dorsi }\end{array}$ & M. semimembranosus & S.E. $^{1}$ \\
\hline GDE & $0.089 \mathrm{a}$ & $0.073 \mathrm{~b}$ & $0.187 \mathrm{c}$ & $0.160 \mathrm{c}$ & 0.006 \\
$\mathrm{PHOS}$ & $4.0 \mathrm{a}$ & $3.2 \mathrm{a}$ & $12.6 \mathrm{~b}$ & $12.1 \mathrm{~b}$ & 0.3 \\
$\mathrm{PHOS} / \mathrm{GDE}$ & $46 \mathrm{a}$ & $46 \mathrm{a}$ & $70 \mathrm{~b}$ & $79 \mathrm{~b}$ & 4 \\
$\mathrm{GP}$ & $96.4 \mathrm{a}$ & $122.1 \mathrm{~b}$ & $182.9 \mathrm{c}$ & $160.5 \mathrm{c}$ & 5.7 \\
$\mathrm{pH}_{35}$ & $6.64 \mathrm{a}$ & $6.81 \mathrm{bc}$ & $6.71 \mathrm{ab}$ & $6.87 \mathrm{c}$ & 0.03 \\
$\mathrm{pH}_{\mathrm{u}}$ & $6.22 \mathrm{a}$ & $6.08 \mathrm{~b}$ & $5.56 \mathrm{c}$ & $5.69 \mathrm{~d}$ & 0.03 \\
\hline
\end{tabular}

${ }^{1}$ S.E. $=$ standard error of the mean. Different letter within a row means a significant difference $(\mathrm{P}<0.05)$ between the values. 
Table 2 . The activity of GDE ( $\Delta \mathrm{abs} / \Delta \mathrm{min})$, the activity of PHOS (U/g muscle), the ratio between PHOS and GDE activities, glycolytic potential (mmol LA equiv./kg) and $\mathrm{pH}_{35}$ and $\mathrm{pH}_{\mathrm{u}}$ values in bovine muscles.

\begin{tabular}{lccc}
\hline & $\begin{array}{c}\text { Slow Twitch and Oxidative } \\
\text { muscle } \\
M . \text { masseter }\end{array}$ & $\begin{array}{c}\text { Fast Twitch and Glycolytic } \\
\text { muscle }\end{array}$ \\
\hline GDE & $0.047 \mathrm{a}$ & $0.091 \mathrm{~b}$ & S.E. $^{1}$ \\
$\mathrm{PHOS}$ & $1.3 \mathrm{a}$ & $8.0 \mathrm{~b}$ & 0.004 \\
$\mathrm{PHOS} / \mathrm{GDE}$ & $30 \mathrm{a}$ & $86 \mathrm{~b}$ & 0.3 \\
$\mathrm{GP}$ & $82.3 \mathrm{a}$ & $239.5 \mathrm{~b}$ & 6 \\
$\mathrm{pH}$ & $6.80 \mathrm{a}$ & $5.98 \mathrm{~b}$ & 6.3 \\
$\mathrm{pH}_{\mathrm{u}}$ & $6.30 \mathrm{a}$ & $5.48 \mathrm{~b}$ & 0.02 \\
$\mathrm{n}=19$ except for phosphorylase and ratio PHOS/GDE when $\mathrm{n}=12$. & \\
${ }^{1} \mathrm{~S} . \mathrm{E} .=$ standard error of the mean. Different letter within a row means a significant difference $(\mathrm{P}<0.001)$ \\
between the values.
\end{tabular}

